\title{
Productivity polarization and sectoral dynamics in European regions
}

\author{
Davide Fiaschi *, Andrea Mario Lavezzi \\ Dipartimento di Scienze Economiche, Università di Pisa, Via Ridolfi 10, 56124 Pisa, Italy \\ Dipartimento di Studi su Politica, Diritto e Società, Università di Palermo, Piazza Bologni 8, 90134 Palermo, Italy
}

Received 10 October 2006; accepted 2 March 2007

Available online 23 May 2007

\begin{abstract}
We show that the distribution dynamics of productivity in European regions displays polarization with a nonlinear growth path. We investigate the factors explaining this behavior focusing in particular on sectoral composition. The $\beta$-convegence analysis reveals that initial shares of Manufacturing and Other Market Services have a nonlinear impact on growth, while spatial effects are not statistically significant. By decomposing the dynamics of aggregate productivity in terms of sectoral dynamics, we show that productivity in Manufacturing, Non Market Services, and Other Market Services does not converge, for the complex interaction of technological spillovers and specialization effects. (C) 2007 Elsevier Inc. All rights reserved.
\end{abstract}

JEL classification: C14; C21; L7; L8; L9; O11; O14; O40

Keywords: Distribution dynamics; Conditional convergence; Nonparametric methods; Sectoral analysis

\section{Introduction}

In this paper we analyze convergence in labor productivity across European regions. This issue has gained considerable importance given the primacy of economic cohesion between different areas of Europe among the priorities of European policy makers (see, e.g. European Commission, 2004). Moreover, regions of Europe offer an interesting labo-

\footnotetext{
${ }^{*}$ Corresponding author. Address: Dipartimento di Scienze Economiche, Università di Pisa, Via Ridolfi 10, 56124 Pisa, Italy. Tel.: +39 050 2216208; fax: +39 0502216384.

E-mail address: dfiaschi@ec.unipi.it (D. Fiaschi).
} 
ratory to test the empirical plausibility of different theories of growth and convergence (see, e.g. Galor, 1996). European regions display wide heterogeneity along certain dimensions such as economic structure and initial conditions. But they show a high degree of homogeneity along other dimensions, like economic and democratic institutions, not typically found in cross-country analyses. The lack of relevant institutional and economic barriers across European regions makes this sample particularly well-suited to detect possible patterns of economic agglomeration, specialization and technological spillovers, issues which still do not appear completely integrated with the studies on growth and convergence.

In this paper we study the cross-region distribution dynamics of aggregate productivity and show that it tends to polarization. We propose an explanation of this pattern by focusing on the composition of output across regions. This approach has not received particular attention so far, with the notable exceptions of Bernard and Jones (1996a,b).

The paper is close to Esteban (2000), and proposes a framework similar to Paci and Pigliaru (1997) and Le Gallo and Dall'Erba (2005) but our analysis, based on distribution dynamics and nonparametric regressions, allow us to uncover various nonlinearities present in the data (related papers are also Fagerberg and Verspagen (1996) and López-Bazo et al. (1999)). In general, there is not a consensus on the dynamics of European regions, also because results strongly depend on the sample and the periods considered for the analysis (see Magrini (2004) for a survey).

The paper is divided in four main sections: in Section 2 we demonstrate the emergence of two peaks in the distribution of productivity and the presence of nonlinearities in the growth path of European regions. In Section 3 we provide descriptive statistics on the regions belonging to the two peaks. In Section 4 we carry out an econometric analysis of the determinants of the two peaks, and identify a relevant role for the initial sectoral composition. We then study the within-sector dynamics, relate it to the distribution dynamics of aggregate productivity and identify the sectoral contribution to growth. Section 5 contains a summary of results and some concluding remarks.

\section{Existence of two peaks in the distribution of productivity}

In this section we analyze the dynamics of aggregate productivity by applying the concept of $\sigma$-convergence and nonparametric methods. We measure productivity by GVA per worker in each region. ${ }^{1}$ Data are from Cambridge Econometrics (2004), and refer to 191 regions belonging to fifteen states of the European Union (Austria, Belgium, Denmark, Finland, France, Germany, Greece, Ireland, Italy, Luxembourg, Netherlands, Portugal, Spain, Sweden, United Kingdom) for the period 1980-2002. The classification criterion of regions broadly corresponds to the NUTS2 classification of Eurostat, which closely reflects the administrative definition of individual countries. ${ }^{2}$

\footnotetext{
${ }^{1}$ Lack of data on capital stocks at regional level prevents use from studying the dynamics of total factor productivity.

${ }^{2}$ German regions include only those from former West Germany. Data are in constant 1995 Euros. The list of regions is in Fiaschi and Lavezzi (2007). European regions have not a clear counterpart in the US administrative classification as their population size is, on average, smaller than the one of a US state and larger than the one of a US county.
} 


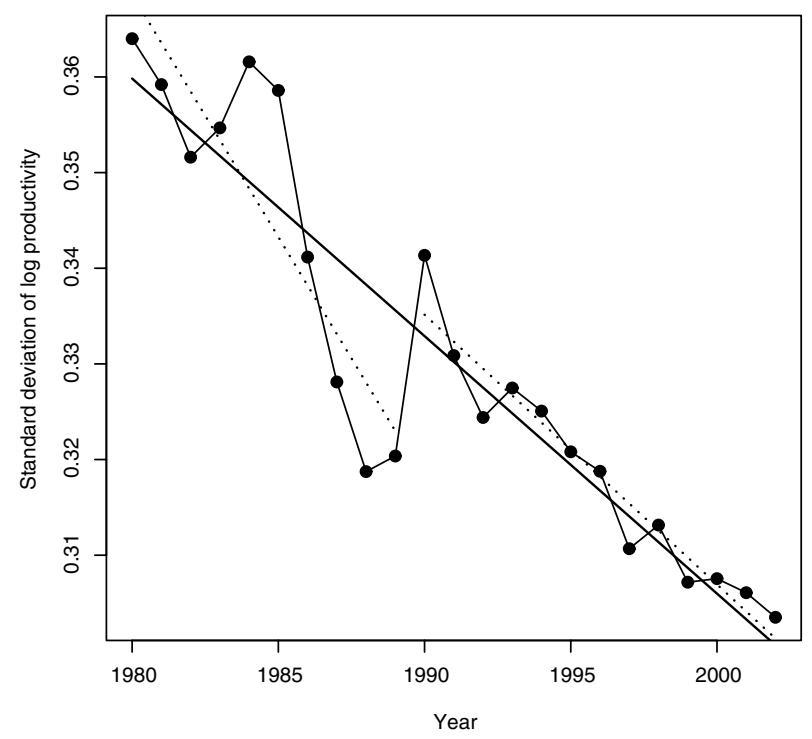

Fig. 1. $\sigma$-Convergence in productivity.

\subsection{Sigma-convergence and distribution dynamics}

Fig. 1 reports the values of the standard deviation of log productivity across regions, $\sigma_{t}$, from 1980 to 2002. Instead, Fig. 2 shows the estimated densities of the whole distribution of productivity across regions in 1980 and in 2002, along with the ergodic distribution, representing the long-run limit (in Fig. 2 productivity is expressed with respect to the sample average of the period). ${ }^{3}$ A linear regression in Fig. 1 shows that $\sigma_{t}$ significantly declines over the period 1980-2002. According to the definition of Barro and Sala-i-Martin (2004, p. 44), the sample displays $\sigma$-convergence. However, we observe that in the subperiod 1980-1989 the pace of convergence is faster than that in 1990-2002, as shown by the dotted lines in Fig. 1, representing the estimates for the two subperiods.

Fig. 2 shows that the reduction in $\sigma_{t}$ is the result of the decrease in the mass at the extreme tails of distribution. The appearance of two peaks around 0.8 and 1.2 , however, shows a tendency to polarization. Polarization distinctly emerges comparing the densities in 1980, 2002, and the ergodic distribution: the peaks become more and more pronounced over time, and in the long-run polarization tends to increase. ${ }^{4}$ We tested the hypothesis of

\footnotetext{
${ }^{3}$ Densities are estimated with Gaussian kernels with normal optimal smoothing, see Bowman and Azzalini (1997, p. 31). All computations are done with R (R Development Core Team, 2004). Codes and data are available in the authors' websites: http://www-dse.ec.unipi.it/persone/docenti/fiaschi/ and http://www.unipa.it/ lavezzi/.

4 The procedure to compute the ergodic distribution follows Johnson (2005) (the author kindly helped us, by providing the instructions now available at http://irving.vassar.edu/faculty/pj/pj.htm). The ergodic distribution solves $f_{\infty}(z)=\int_{0}^{\infty} g_{\tau}(z \mid x) f_{\infty}(x) \mathrm{d} x$ where $z$ and $x$ are two levels of the variable, $g_{\tau}(z \mid x)$ is the density of $z$, given $x, \tau$ periods ahead. In our computations we set $\tau=10$. To estimate $g_{\tau}(z \mid x)$, the stochastic kernel, we estimated the joint density of $z$ and $x, g(z, x)$, and the marginal density of $x, f(x)$. In the estimation of $g(z, x)$ we followed Johnson (2005), who used the adaptive kernel estimator discussed by Silverman (1986, p. 100), in which the window of the kernel (Gaussian in our case) increases when the density of observations decreases.
} 


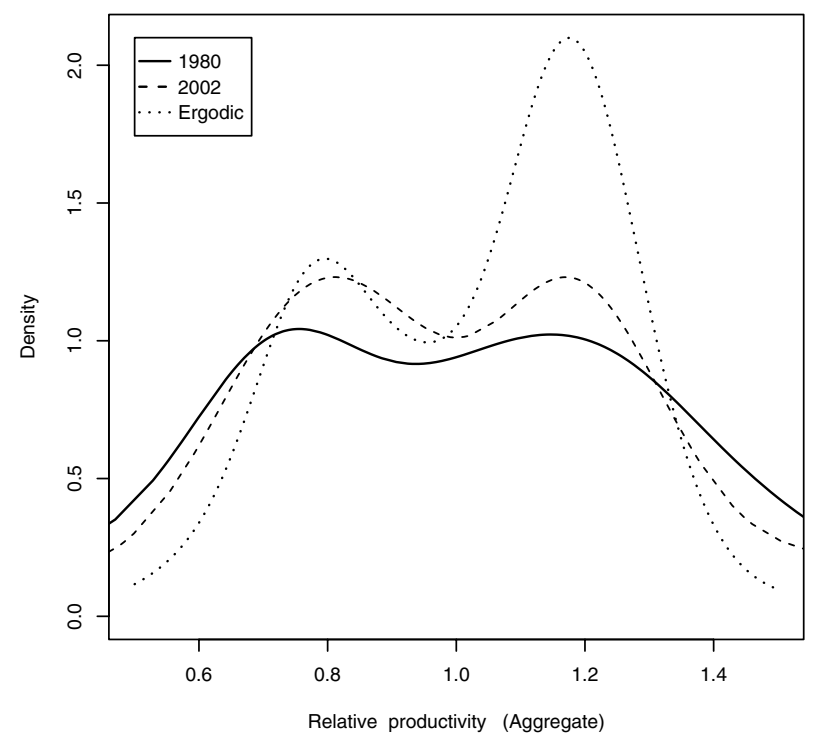

Fig. 2. Distribution dynamics of productivity.

unimodality of the distribution of productivity in 1980 and 2002 by a bootstrap procedure suggested by Efron and Tibshirani (1993, p. 227), and rejected the null hypothesis at $1 \%$ in both years. 5

Having identified a tendency to polarization in the distribution of regional productivities, we proceed by estimating the growth path. In particular, we pool all observations and run a nonparametric estimation of the relation between the growth rate and level of productivity:

$$
\text { PROD.GR }{ }_{t}^{i}=\alpha+s\left(\operatorname{PROD} \cdot \mathrm{REL}_{t}^{i}\right)+\epsilon_{t}^{i},
$$

where PROD.GR ${ }_{t}^{i}$ is growth rate in year $t, \mathrm{PROD}_{\mathrm{REL}}{ }_{t}^{i}$ is relative productivity of region $i$ in year $t$ with respect to the average of the period, $s(\cdot)$ is an unknown function, and $\epsilon_{t}^{i}$ is a random component. ${ }^{6}$

Fig. 3 displays the results (the horizontal line indicates the average growth rate of the sample over the period, equal to $1.68 \%$ ), while Table 1 reports the statistics of the nonparametric regression in Eq. (1).

Table 1 and Fig. 3 show that the relationship between productivity growth, PROD.GR, and relative productivity, PROD.REL, is statistically significant and strongly nonlinear: the estimated degrees of freedom of the smooth term $s(\cdot)$ are much higher than 1 , indicating that there is no evidence of a linear relation. ${ }^{7}$

\footnotetext{
${ }^{5}$ Our result is in contrast with López-Bazo et al. (1999) who find a tendency to convergence in labor productivity across European regions. This may depend on the differences in the sample: they studied 140 regions from twelve countries for the period 1983-1992.

${ }^{6}$ The statistical package mgcr based on the R environment, if not stated differently, is used for all the nonparametric regressions (see Wood, 2006). See Appendix B for details on the method of estimation and interpretation of the results.

${ }^{7}$ See Appendix B for more details.
} 


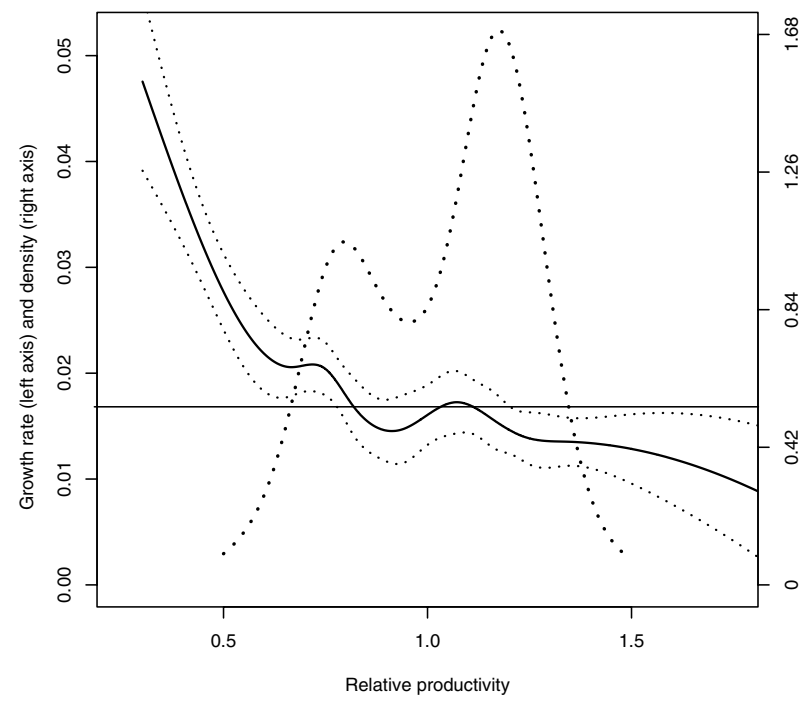

Fig. 3. Growth path of productivity.

Table 1

Estimation of Eq. (1)

Parametric coefficients

$\hat{\alpha}$

$0.014^{* * *}$

Nonparametric coefficients

PROD.REL

$7.421^{* * *}$

$\bar{R}^{2}$

GCV score $\left(\times 10^{3}\right)$

1.228

Dev. expl.

0.026

Obs.

Dependent variable: PROD.GR.

${ }^{* * *}$ Indicates significance at $1 \%$. For the nonparametric terms we report the estimated degrees of freedom (EDF).

In Fig. 3 we observe that the growth path intersects the horizontal line in three points, approximately at the values of $0.8,1$ and 1.2 (the dotted line in figure are the $95 \%$ confidence intervals of the estimate). Given the shape of the growth path, we should observe persistence in the proximity of 0.8 and $1.2{ }^{8}$ In particular, this implies a shrinking of the distribution since regions with productivity below 0.8 or above 1.2 converge toward the range $[0.8,1.2]$; however, regions in that range should have a growth rate not statistically different from the average. This produces the twin-peaked ergodic distribution in Fig. 3 (these peaks are already emerging in 2002, as shown in Fig. 2).

The estimation based on the pooling of observations, however, represents an average behavior, and could ignore heterogeneity in the growth paths of individual regions. There-

\footnotetext{
${ }^{8}$ In Appendix A we regress the average annual growth rate on the relative productivity level in 1980, and obtain a negative and highly significant coefficient. This would indicate the presence of absolute $\beta$-convergence. However, by a comparison with a nonlinear specification, this result appears to depend from the imposition of a linear structure, as the nonlinearities identified in Fig. 3 remain.
} 


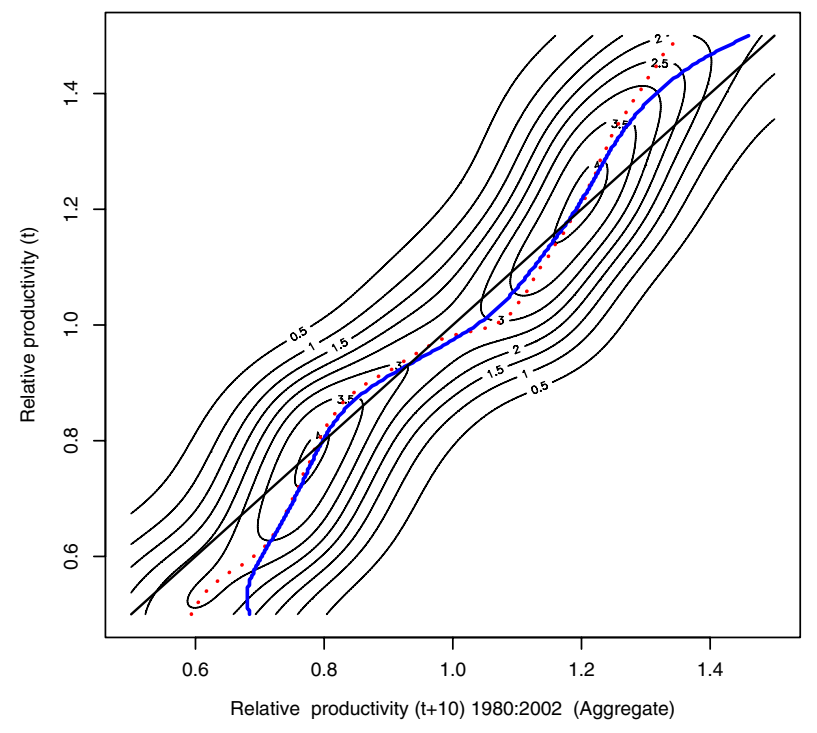

Fig. 4. Stochastic kernel of productivity.

Table 2

Number of regions in Cluster $\mathrm{L}$ and Cluster $\mathrm{H}$

\begin{tabular}{lll}
\hline & 1980 & 2002 \\
\hline Cluster L & 44 & 53 \\
Cluster H & 39 & 55 \\
Total & $83(43 \%)$ & $108(57 \%)$ \\
\hline
\end{tabular}

fore, we estimate the stochastic kernel (see Fig. 4), indicating for each level of productivity at time $t$ the probability distribution of productivity at $t+\tau$ (in our case we set $\tau=10$ ). ${ }^{9}$ In Fig. 4 we also report a solid line representing the estimated median value at $t+10$ conditional on the value at time $t$, a dotted line indicating the "ridge" of the stochastic kernel, and a $45^{\circ}$ line.

The intersections between the solid line and the $45^{\circ}$ line identify the three productivity levels around 0.8, 0.9 and 1.2 where the actual level and the estimated median value are equal. For productivity levels below 0.8 and between 0.9 and 1.2 , the probability of higher level after 10 years is higher than the probability of a lower level, while the opposite holds for productivity levels between 0.8 and 0.9 and above 1.2. This picture supports the claim of the existence of polarization in the dynamics of productivity around 0.8 and 1.2.

We add and subtract one percentage point to 0.8 and 1.2 and define the regions with productivity between 0.7 and 0.9 as belonging to a low-productivity cluster (Cluster L), and the regions with productivity between 1.1 and 1.3 as belonging to a high-productivity cluster (Cluster $\mathrm{H}$ ). Table 2 shows that the share of regions in the two clusters is substantial and increasing over time (from $43 \%$ to $57 \%$ of the sample), while Table 3 confirms that

\footnotetext{
${ }^{9}$ See Quah (1997) for more details.
} 
Table 3

Transition probabilities between Cluster L and Cluster $\mathrm{H}$

\begin{tabular}{lll}
\hline & 2000 & \\
\cline { 2 - 3 } & Cluster L & Cluster H \\
\hline 1980 & & \\
Cluster L & 0.77 & 0.02 \\
Cluster H & 0 & 0.77 \\
\hline
\end{tabular}

these productivity ranges are characterized by persistence: in fact, for regions in both clusters in 1980, the probability to be in the same cluster in 2002 is $77 \%$.

In the next section we provide a description of the regions in the two productivity clusters at the beginning and at the end of the period.

\section{Descriptive statistics of regions in the two clusters}

Table 4 provides information on the characteristics of the regions in the two clusters at the beginning and at the end of the period of observation. ${ }^{10}$ We consider, besides the growth rate of productivity (PROD.GR), the rate of investment (INV), its value relative to sample average (INV.REL), the growth rate of employment (EMP.GR), the density of economic activity (ECO.DEN), measured by the log of GVA per $\mathrm{km}^{2}$, population density (POP.DEN), measured by the (log of) population per $\mathrm{km}^{2}$, and an index of spatial autocorrelation of productivities (SPATIAL.DIX). We use $G^{*}$, the statistics proposed by Ord and Getis (1995), as our measure of spatial autocorrelation (see also Le Gallo and Dall'Erba, 2005): a positive (negative) value means that the region belongs to a spatial cluster of high-productivity (low-productivity) regions. The higher the value, the higher the productivity level of the cluster. ${ }^{11}$

PROD.GR in Table 4 shows that Cluster $\mathrm{L}$ and Cluster $\mathrm{H}$ have similar average growth rates of productivity in the two periods. Investment behavior, on the contrary, is different for the two clusters: regions in Cluster $\mathrm{H}$ invest more than average, while regions in Cluster L invest less. The growth rate of employment EMP.GR is also very similar in the two clusters and increasing over time. Starting from similar levels, economic density becomes strongly higher in Cluster H. Population density is increasing in both clusters, and it is higher in Cluster L in both periods. Finally, SPATIAL.DIX appears stable: it shows that regions in Cluster $\mathrm{H}$ belong to high-productivity clusters, while regions in Cluster L belong to low-productivity clusters.

Summarizing: with respect to Cluster L, Cluster $\mathrm{H}$ appears to be composed by regions with higher levels of investment, a much higher economic density and a lower population

\footnotetext{
${ }^{10}$ To reduce cyclical factors we consider 5 -year averages.

${ }^{11}$ Index $G^{*}$ is based on the differences between the productivity of region $i$ 's neighbors and the average productivity of the sample. These differences are weighted by a (row-normalized) matrix computed using the inverse of squared distance in $\mathrm{km}$ between the centroids of the regions. We used the median distance from every region as the cut-off value to define the neighbors of regions $i$ (other cut-off values do not affect our results). $G^{*}$ is preferable to other commonly used indices like local Moran's and Geary's, as the latter highlight correlations between the level of some characteristic at different locations, while the former identifies "spatial clustering of high [and low] values" (Anselin, 1995, p. 102).
} 
Table 4

Variables characterizing regions in Cluster L and Cluster $\mathrm{H}$

\begin{tabular}{lcccc}
\hline Variable & \multicolumn{2}{c}{ Cluster L } & \multicolumn{1}{c}{ Cluster H } \\
\cline { 2 - 4 } & $1980-84$ & $1998-2002$ & $1980-84$ & $1998-2002$ \\
\hline PROD.GR & 0.024 & 0.012 & 0.022 & 0.011 \\
INV & 0.2 & 0.18 & 0.22 & 0.23 \\
INV.REL & 0.96 & 0.87 & 1.05 & 1.05 \\
EMP.GR & -0.003 & 0.012 & -0.005 & 0.013 \\
ECO.DEN & 2.35 & 5.86 & 2.34 & 10.14 \\
POP.DEN & 0.27 & 0.48 & 0.16 & 0.35 \\
SPATIAL.DIX & -1.64 & -1.63 & 3.07 & 3.09 \\
\hline
\end{tabular}

density. Low-productivity and high-productivity regions, finally, appear to be clustered in space.

Next, we analyzed the sectoral composition of GVA and employment in the two clusters in 1980 and 2002 considering the following sectors: Agriculture (AGR), Manufacturing (MAN), Mining and Energy Supply (MINEG), Construction (CONSTR), Non Market Services (NMS), Financial Services (FIN), Hotels and Restaurants (HOT), Transport and Communications (TRANSP), ${ }^{12}$ Wholesale and Retail (WHR) and Other Market Services $(\mathrm{OS}) .{ }^{13}$

Over the period of observation, Cluster $\mathrm{H}$ is mainly characterized by regions with a relative prevalence in terms of share of GVA and share of employment of the sectors of Manufacturing, Non Market Services, Financial Services and Other Services, while Cluster L of Agriculture, Mining and Energy Supply, Hotels and Restaurants, and Wholesale and Retail. A higher share of Transport and Communications in aggregate output characterizes Cluster L; on the contrary, a higher share of employment share in Transport and Communication characterizes Cluster H. ${ }^{14}$ Finally, Figs. 5 and 6 offer a visual representation of the two clusters in 1980 and in 2002 in order to evaluate spatial patterns in the dynamics of productivity.

Regions in Cluster $\mathrm{H}$ mainly belong to the geographical core of Europe, while periphery is essentially characterized by regions in Cluster L. A comparison between 1980 and 2002 suggests that this geographical clustering reinforced over the period. In particular, the geographical core of Europe becomes more characterized by regions of Cluster $\mathrm{H}$ as some French, German and the Swedish regions closer to continental Europe enter Cluster $\mathrm{H}$ in 2002. Periphery, instead, becomes more characterized by regions in Cluster L as some Spanish, Italian and UK regions enter Cluster L in 2002. Ireland represents an exception, being a country in the periphery in which a region moved from Cluster L to Cluster $\mathrm{H}$ between 1980 and 2002 .

This geographical pattern highlights a country-specific effect, as most of regions in Italy, Spain and UK are in Cluster L, while most of regions in Belgium, France, Germany, Netherlands and Austria are in Cluster H in 1980 and, especially, in 2002. Between the 2 years, it appears that these countries became more homogeneous.

\footnotetext{
12 TRANSP includes air and water transportation services as well as telecommunications.

13 OS includes real estate activities, computer and related activities (e.g. hardware and software consultancy), legal services, research and development. In general these appear as high-value added, high-skill services.

${ }^{14}$ See Fiaschi and Lavezzi (2007) for more details.
} 


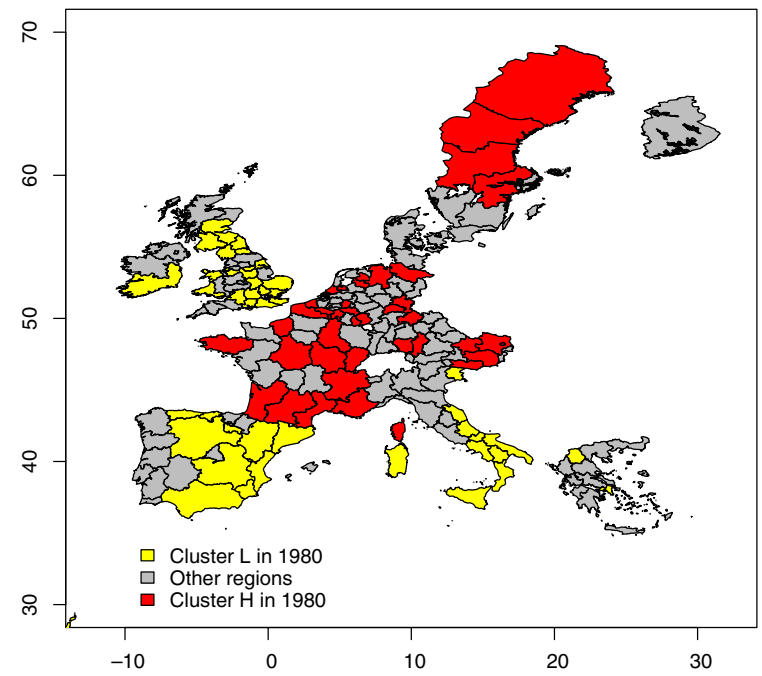

Fig. 5. Productivity clusters in 1980 .

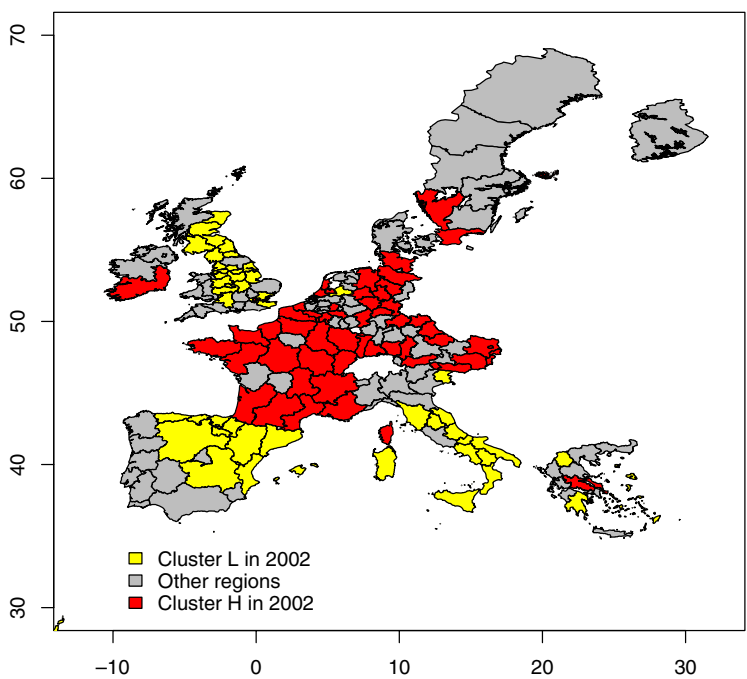

Fig. 6. Productivity cluster in 2002.

\section{Explaining the clusters}

In this section we provide an explanation of the nonlinearities in the growth path and of the emergence of two productivity peaks, and show that a crucial role is played by the sectoral composition of output.

\subsection{Sectoral composition and conditional $\beta$-convergence}

Here we investigate whether there exists evidence of conditional $\beta$-convergence (see Barro and Sala-i-Martin, 2004, p. 44) but, differently from most of the literature, we 
use a nonparametric specification and pay particular attention to sectoral composition. The nonparametric specification allows us to capture more general forms of the effects of the regressors and produces in general a better fit than the linear specification (see Fiaschi and Lavezzi, 2007). In particular, we estimate the following generalized additive model:

$$
\overline{\mathrm{PROD} . G R}^{i}=\alpha+s_{1}\left(\log \left(\operatorname{PROD} \cdot \operatorname{REL1980}{ }^{i}\right)\right)+\sum_{k=2}^{K} s_{k}\left(Z_{k}^{i}\right)+\epsilon^{i},
$$

where ${\overline{\mathrm{PROD}} \cdot \mathrm{GR}^{i}}^{i}$ is the average annual growth rate of productivity, PROD.REL1980 is the productivity level in $1980, Z_{k}^{i}$ represents the $k$-th explanatory variable in region $i$, and $s_{k}(\cdot)$ is an unknown function ( $K$ is the number of explanatory variables).

In particular we consider: variables suggested by the Solow model (INV, EMP.GR), the initial productivity level (PROD.REL1980), variables reflecting agglomeration effects (ECO.DEN and POP.DEN), a variable proxying for spatial effects (SPATIAL.IDX), and variables describing the composition of output, in particular its initial value (AGR1980, MAN1980, COSTR1980, NMS1980, FIN1980, HOT1980, TRANSP1980, WHR1980 and OS1980). Finally, we introduce country dummies. ${ }^{15}$

The growth rate of employment EMP.GR is augmented by the rate of depreciation of capital, ${ }^{16}$ but not by the long-run trend of productivity, as the latter is already taken into account by considering productivity in relative terms. ECO.DEN and POP.DEN should control for the effects of economic and demographic agglomeration on productivity, ${ }^{17}$ while the possible positive effect of proximity to high-productivity regions should be captured by SPATIAL.IDX.

Considering the composition of output leads to a better definition of the initial level of productivity of a region, and provides useful information on the role of different sectors. For example, given some level of initial productivity, regions with a high initial share in the service sector can be expected to grow relatively low, if the service sector is growing at low growth rate and the employment share in that sector does not decrease. ${ }^{18}$

Finally, we introduce country dummies to capture the effects of variables whose dimension is typically national, but for which we have not data: political institutions, labor markets, educational systems, etc. ${ }^{19}$

Table 5 contains the results of the estimation of Eq. (2). ${ }^{20}$ Model (1) includes all variables as regressors. Model (2) controls for the relevance of the country dummies by excluding them. Model (3) considers a proxy for the level of human capital of the country as a possible substitute for the country dummies. We chose as proxy the fraction of workers

\footnotetext{
$\overline{15}$ Variables not referred to the initial year are averages between 1980 and 2002. Sectoral variables refer to the share of sectoral GVA on total GVA for a region. We do not include the MINEG sector in the initial composition of output to avoid perfect collinearity with the other sectoral shares.

${ }^{16}$ Given that we do not have data on capital at regional level, we use the value of 0.03 proposed by Mankiw et al. (1992).

${ }^{17}$ See Ciccone and Hall (1996).

${ }^{18}$ Fagerberg and Verspagen (1996, p. 438), make similar considerations on possible disadvantages deriving from a high share of agricultural output. A control for the initial composition of output in an analysis of $\beta$-convergence is also found in Barro and Sala-i-Martin (1991, p. 146), although its inclusion aims at filtering out from the error term the effects of sectoral shocks. Their results show that, for European regions and US states, this control adds stability over time to the coefficient on initial output.

${ }^{19}$ Fiaschi and Lavezzi (2007) contains the descriptive statistics for the variables used in the regressions.

${ }^{20}$ See Appendix B for details.
} 
Table 5

Results of the estimation of Eq. (2)

\begin{tabular}{|c|c|c|c|c|}
\hline Coefficients & (1) & (2) & (3) & (4) \\
\hline Country dummies & YES & $\mathrm{NO}$ & NO & YES \\
\hline Intercept & $0.0184^{* * *}$ & $-0.0168^{* * *}$ & $-0.0113^{* * *}$ & $0.0138^{* * *}$ \\
\hline $\log ($ PROD.REL1980) & $3.360^{* * *}$ & $1^{* * *}$ & $(-0.0252)^{* * *}$ & $9.981^{* * *}$ \\
\hline $\log (\mathrm{INV})$ & $3.063^{* * *}$ & 3.165 & $2.871^{\circ}$ & $2.329^{* *}$ \\
\hline $\log ($ EMP.GR $)$ & $5.516^{* * *}$ & $7.208^{* * *}$ & $6.130^{* * *}$ & $8.284^{* * *}$ \\
\hline $\log (\mathrm{ECO} . \mathrm{DEN})$ & $3.691^{* * *}$ & $1^{* * *}$ & $(0.0149)^{* * *}$ & $4.226^{* * *}$ \\
\hline $\log ($ POP.DEN $)$ & $3.839^{* * *}$ & $5.859^{* * *}$ & $5.811^{* * *}$ & $4.349^{* * *}$ \\
\hline SPATIAL.IDX & 3.548 & 1 & & \\
\hline AGR1980 & 1.577 & $1^{* *}$ & $(0.0197)^{*}$ & \\
\hline MAN1980 & 1.793 & $2.944^{*}$ & $3.349^{*}$ & $3.499^{*}$ \\
\hline COSTR 1980 & 2.420 & $7.008^{* * *}$ & $2.776^{* * *}$ & \\
\hline NMS1980 & 1 & 2.747 & $1.374^{*}$ & \\
\hline FIN1980 & $2.812^{*}$ & $6.830^{* *}$ & $5.937^{* * *}$ & $10.370^{* * *}$ \\
\hline HOT1980 & $4.422^{* * *}$ & $4.147^{*}$ & $4.302^{* *}$ & $4.290^{* * *}$ \\
\hline TRANSP1980 & $1.173^{* *}$ & $1.346^{* * *}$ & $(0.0629)^{* * *}$ & $(0.0351)^{* * *}$ \\
\hline WHR1980 & $5.147^{* * *}$ & 1.813 & $(0.0355)^{* *}$ & $(0.0279)^{*}$ \\
\hline OS1980 & $5.355^{* * *}$ & $4.643^{* * *}$ & $3.942^{* *}$ & $5.142^{* * *}$ \\
\hline LFTE & & & $(0.0325)^{* * *}$ & \\
\hline $\bar{R}^{2}$ & 0.89 & 0.76 & 0.76 & 0.90 \\
\hline Dev. expl. & $92.5 \%$ & $82.2 \%$ & $81.3 \%$ & $93.8 \%$ \\
\hline GCV score $\left(\times 10^{5}\right)$ & 7.282 & 14.71 & 13.56 & 6.604 \\
\hline Scale est. $\left(\times 10^{5}\right)$ & 4.853 & 10.65 & 10.47 & 4.202 \\
\hline Obs. & 191 & 191 & 191 & 191 \\
\hline
\end{tabular}

Significance codes: ${ }^{* * *}, 1 \%$, ,**, $1 \%,{ }^{* *}, 5 \%, \cdot{ }^{*} 10 \%$. For the nonparametric terms we report the estimated degrees of freedom (EDF). Terms in parenthesis are coefficient for the variables which enter linearly.

with tertiary education in the labor force, LFTE, for its higher significance with respect to other proxies. ${ }^{21}$ Model (4) represents our preferred specification, obtained from Model (1). ${ }^{22}$ Fig. 7, finally, displays the estimates of the nonlinear components of Model (4).

From Table 5 we see that goodness of fit is generally high (the deviance explained in Model (4) is equal to 93.8\%). From Fig. 7 the relationship between PROD.GR and PROD.REL1980 is monotonically decreasing and strongly significant. Initial productivity has no effects on regions whose initial productivity is close to the average; on the contrary regions starting for instance at $50 \%$ of the average grow on average $2 \%$ more than the regions with average initial productivity.

INV does not appear to have a relevant effect (the magnitude of the effect is about zero for a large range of values). ${ }^{23}$ However, it appears nonlinear: its effect is nonsignificantly different from zero at the extreme values, but it is significantly negative in between.

\footnotetext{
${ }^{21}$ Data are from World Bank (2004). As alternative measures we tried with fractions of population with secondary and tertiary education, and enrollment rates. Data on LFTE are time averages for the all available observations, and are originally expressed at country level. For this reason we attributed to each region the level of its country.

22 Model (4) is selected by eliminating recursively the non-significant variables from Model (1), starting from the least significant.

${ }^{23}$ Fagerberg and Verspagen (1996) obtain a similar result.
} 

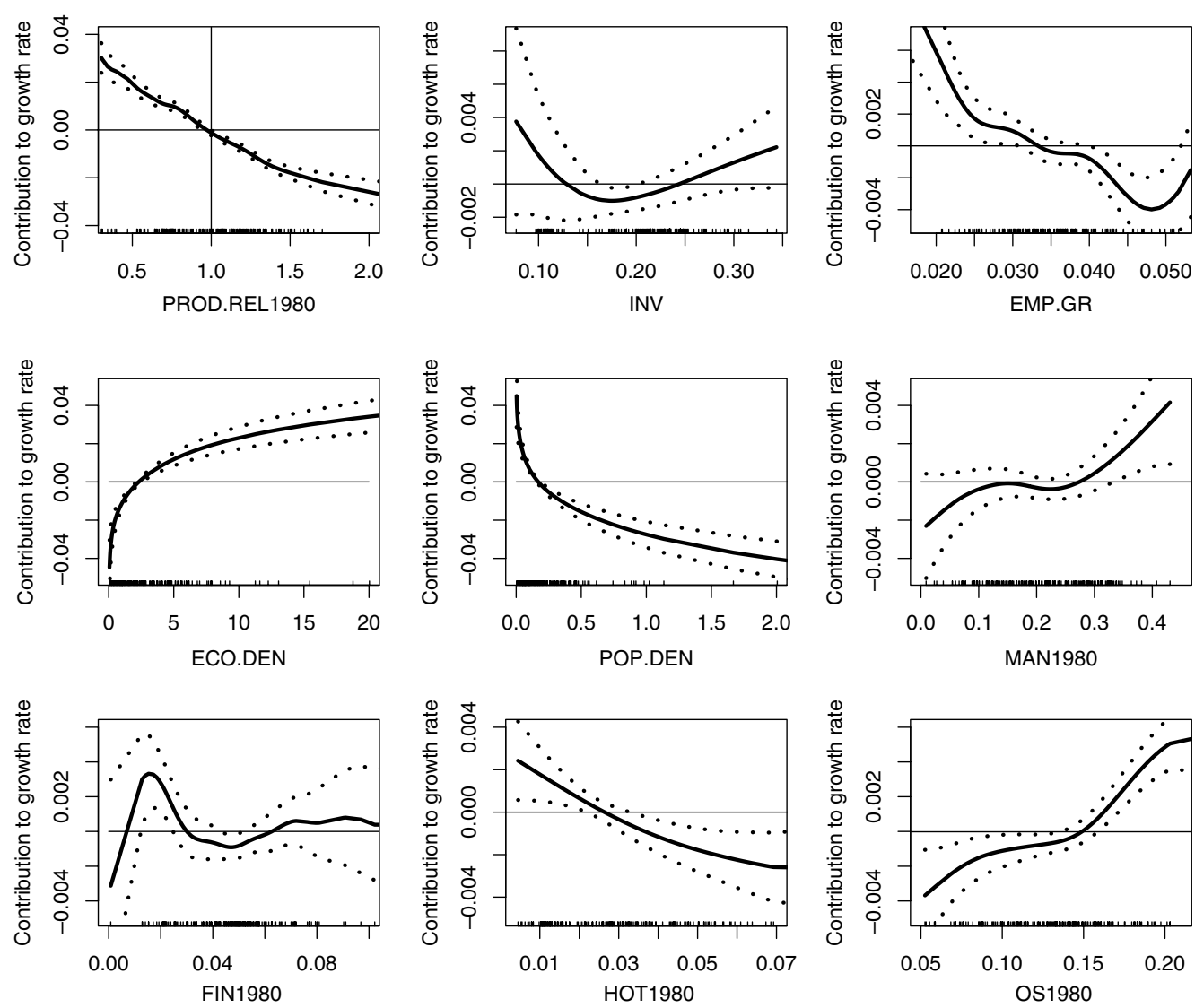

Fig. 7. Significant smooth terms in Model (4) of Table 7.

EMP.GR has the expected shape, being monotonically decreasing, although the magnitude of the effect is rather small. ECO.DEN and POP.DEN have respectively significantly increasing and decreasing effects on growth.

SPATIAL.IDX appears to be nonsignificant. In particular, its effect vanishes in presence of PROD.REL1980 and country dummies, implying that spatial effects are captured by other variables. ${ }^{24}$

Six terms reflecting the initial composition of output are significant at $5 \%$. In particular, two terms enter linearly in Model (4): TRANSP1980 and WHR1980 both with positive sign. MAN1980 exerts a positive effect above a certain threshold (about 0.25); below the effect is nonsignificantly different from zero. FIN1980 has a positive effect for low levels, negative for intermediate levels and not significantly different from zero for high levels. HOT1980 have a monotonically decreasing effect, while OS1980 has a positive and nonlinear effect.

\footnotetext{
${ }^{24}$ Paci and Pigliaru (1997, p. 220) find that spatial autocorrelations across European regions disappear when country dummies are considered.
} 
Overall, the nonlinear relationship between the level of productivity and the growth rate disappears once we control for (i) variables typically used in cross-section regressions, (ii) agglomeration and spatial effects, (iii) the initial sectoral composition of output and (iv) country dummies. However, the nonlinearity is now ascribed to some explanatory variables, most notably the initial share of Manufacturing and Other Services. Having found an important role for the initial composition of output, in the next section we focus on the dynamics of sectoral productivity.

\subsection{On sectoral dynamics}

We studied the dynamics within individual sectors, for both productivity and employment shares in order to relate it to the dynamics of the distribution of aggregate productivity, an exercise in the spirit of Feyrer (2003) and Johnson (2005). In this section we summarize the main results (see Fiaschi and Lavezzi (2007) for more details).

Relative aggregate productivity in region $i, \tilde{y}^{i}$, can be expressed as

$$
\tilde{y}^{i}=\frac{y^{i}}{\bar{y}}=\frac{\sum_{j=1}^{N} y_{j}^{i} \omega_{j}^{i}}{\bar{y}}=\sum_{j=1}^{N}\left(\frac{y_{j}^{i}}{\bar{y}_{j}}\right)\left(\frac{\bar{y}_{j}}{\bar{y}}\right) \omega_{j}^{i}=\sum_{j=1}^{N} \underbrace{\tilde{y}_{j}^{i}}_{\mathrm{RSP}} \underbrace{\left(\bar{y}_{j} / \bar{y}\right)}_{\mathrm{ASP}} \underbrace{\omega_{j}^{i}}_{\mathrm{ES}},
$$

where $y^{i}$ is productivity in region $i$ (total output $Y^{i}$ divided by total employment $L^{i}$ in region $i$ ); $\bar{y}$ is sample average productivity, $\omega_{j}^{i}$ is the employment share of sector $j$ in region $i$ (employment in sector $j$ in region $i, L_{j}^{i}$, divided by total employment in region $i, L^{i}$ ); $\tilde{y}_{j}^{i}$ is the productivity of sector $j$ in region $i$ with respect to the average productivity of sector $j, \bar{y}_{j}$ (time subscripts have been omitted for clarity), $N$ is the number of sectors.

Eq. (3) shows that the distribution dynamics of aggregate productivity can be studied in terms of three components: (i) relative sectoral productivity (RSP); (ii) average sectoral productivity (ASP), and (iii) employment shares (ES).

We would expect convergence in sectoral productivity across regions (RSP) if the same sectoral technology is available in each region: technological spillovers within sectors across regions, therefore, become a key aspect to be taken into account. The second term in Eq. (3), ASP, indicates the differences in sectoral productivities. In the analysis of distribution dynamics of aggregate productivity ASP reflects the weight of the productivity of individual sectors on the total.

The cross-region pattern of sectoral employment ES essentially depends on regional specialization. A related issue is factors' mobility (e.g. interregional flows of labor), that typically should be a source of convergence unless increasing returns prevail. If there are no particular differences in income and preferences across regions, and the output of a sector is not tradeable, then we should observe similar labor shares across regions. On the contrary, if output is tradeable, then we could observe different labor shares in different regions, as production may for instance concentrate in one region to exploit local Marshallian externalities. In this case we should observe divergence both in RSP and in ES in the sector.

Table 6 reports the initial and final values of ASP and average ES for each sector. ${ }^{25}$

\footnotetext{
${ }^{25}$ See Fiaschi and Lavezzi (2007) for the series of these values.
} 
Table 6

ASP and average ES

\begin{tabular}{lllll}
\hline Sector & ASP & & \multicolumn{2}{l}{ Average ES } \\
\cline { 2 - 3 } & 1980 & 2002 & 1980 & 2002 \\
\hline AGR & 0.45 & 0.76 & 0.12 & 0.06 \\
MAN & 0.86 & 1.27 & 0.24 & 0.17 \\
MINEG & 2.68 & 5.03 & 0.02 & 0.01 \\
CONSTR & 0.96 & 0.77 & 0.08 & 0.07 \\
NMS & 0.98 & 0.77 & 0.24 & 0.29 \\
FIN & 2.42 & 1.71 & 0.02 & 0.03 \\
HOT & 0.91 & 0.64 & 0.04 & 0.05 \\
TRANSP & 1.13 & 1.23 & 0.06 & 0.06 \\
WHR & 0.80 & 0.75 & 0.13 & 0.15 \\
OS & 3.47 & 1.88 & 0.05 & 0.12 \\
\hline
\end{tabular}

MAN, MINEG, FIN, TRANSP and OS have above average values of ASP in 2002. In particular, MAN, MINEG and TRANSP have increasing values over the period. NMS, MAN, WHR and OS instead present the largest values of average ES, but the share of MAN is strongly decreasing over the period (this also holds for AGR).

We analyzed the within-sector dynamics by focusing on four aspects: (i) the within-sector distribution dynamics of RSP, which should reveal whether the same sector in different regions is converging in terms of productivity; (ii) the within-sector distribution dynamics of ES, which provides information on possible patterns of regional specialization; (iii) the relationship between RSP and ES, which indicates whether increases in RSP are related to decreases in ES, suggesting that diminishing returns are at work, or to increases in ES, suggesting that specialization effect dominates ${ }^{26}$; and (iv) the technological spillovers within the sector, which should provide an essential contribution to the explanation to the dynamics of productivity within the sector.

The first two aspects can be studied by estimating the densities of RSP and ES, while the third aspect can be analyzed by a nonparametric regression between ES and RSP; the last aspect requires the definition of the process driving individual sectors' productivities.

Bernard and Jones (1996a) suggest that the dynamics of productivity of sector $j$ in region $i$ at period $t, y_{j, t}^{i}$, can be described by

$$
\ln y_{j, t}^{i}=\gamma_{j}\left(Z^{i}\right)+\lambda_{j}\left(\ln \left(\check{y}_{j, t}^{i}\right)\right)+\ln y_{j, t-1}^{i}+\ln \varepsilon_{j, t}^{i},
$$

where $\check{y}_{j, t}^{i}=y_{j, t}^{i} / y_{j, t}^{L}, y_{j, t}^{L}$ is the productivity of the technological leader in sector $j$ at time $t$ (i.e. $y_{j, t}^{L}=\max _{i} y_{j, t}^{i}$ ), $Z^{i}$ is a vector of characteristics of region $i, \lambda_{j}(\cdot)$ is a function such that $\lambda_{j}(0)=0$, and $\varepsilon_{j, t}^{i}$ is a i.i.d. random shock. The shape of $\lambda_{j}(\cdot)$ estimates the intensity of technological spillovers. ${ }^{27}$

From Eq. (4) we have that

$$
\check{g}_{j, t}^{i} \cong \ln \left(\frac{\check{y}_{j, t}^{i}}{\check{y}_{j, t-1}^{i}}\right)=\gamma_{j}\left(Z^{i}\right)-\gamma_{j}\left(Z^{L}\right)+\lambda_{j}\left(\ln \check{y}_{j, t-1}^{i}\right)+\ln \check{c}_{j, t}^{i} .
$$

\footnotetext{
${ }^{26}$ By specialization effect we refer to the tendency for regions with higher RSP in a sector to have higher ES.

${ }^{27}$ Within-sector convergence occurs if spillovers increase with the distance from the productivity of the technological leader of the sector. The main difference with respect to Bernard and Jones (1996a) is that we do not assume that $\lambda_{j}(\cdot)$ is linear.
} 


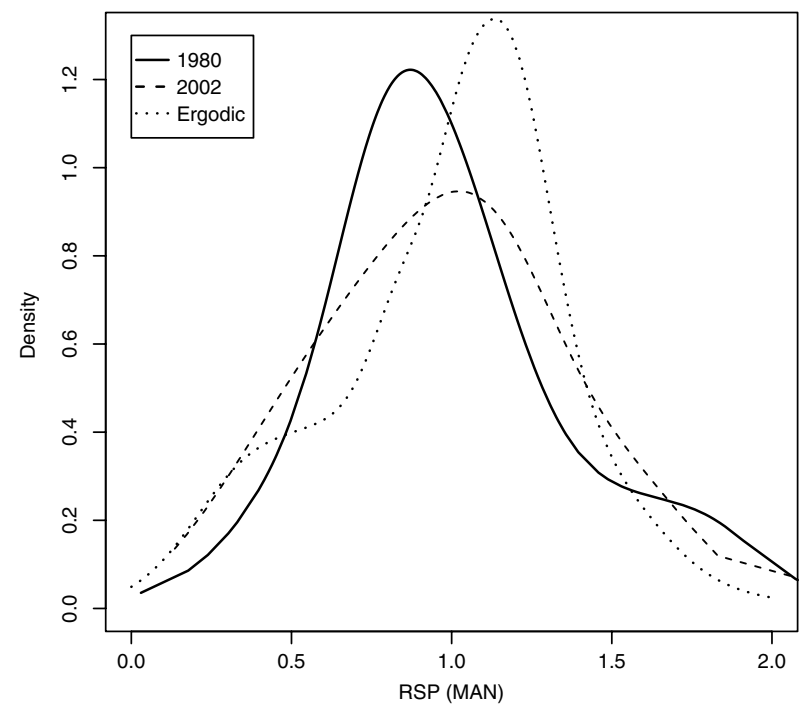

Fig. 8. Distribution dynamics of RSP (MAN).

If we assume that $\gamma_{j}\left(Z^{i}\right)=\gamma_{j}\left(Z^{L}\right) \forall i$, then we have absolute convergence if there exists only one value $\check{y}_{j}^{*}$ such that the estimate $\hat{\lambda}_{j}\left(\ln \check{y}_{j}^{*}\right)=0$ and $\mathrm{d} \hat{\lambda}_{j} / \mathrm{d} \check{y}_{j}<0$ in $\check{y}_{j}^{*}$ (this is a necessary condition for absolute convergence). If the slope of $\hat{\lambda}$ is non-negative in some productivity ranges this does not preclude absolute convergence in the long run, implying only nonconvergence in the transitional dynamics.

We estimated for every sector the dynamics of RSP, of ES, of their relationship and of function $\lambda_{j}(\cdot)$ in Eq. (5). ${ }^{28}$ In the following we report the results for Manufacturing, Other Market Services and Non Market Services, which appear the most important sectors in the explanation of the aggregate productivity dynamics. For a complete account see Fiaschi and Lavezzi (2007).

\subsubsection{Manufacturing}

Fig. 8 shows that RSP is converging toward the average, but the tail at low levels is increasing. Fig. 9 shows that the ES is converging toward lower levels. Fig. 10 highlights that Manufacturing displays specialization effects, as the estimation of the relationship between ES and RSP is always increasing in 1980, while in 2002 it is increasing for RSP below the average and rather flat for higher levels of RSP. Fig. 11 reveals that for high levels of $\breve{y}_{\text {MAN }}$ technological spillovers are at work, but for low levels (below 0.2) technological spillovers are absent. For higher productivity levels the shape of $\hat{\lambda}_{\text {MAN }}$ leads to convergence. This contributes to the explanation of the dynamics in Fig. 8.

\subsubsection{Other Market Services}

RSP in the OS sector does not converge as shown in Fig. 12: two peaks around 0.5 and 1.5 are evident. ES displays a nonconverging pattern: on average ES increases but disper-

\footnotetext{
${ }^{28}$ We estimated Eq. (5) without controlling for the characteristics of region $i, Z^{i}$, and for the characteristics of leader region $L, Z^{L}$ : the intercept of the estimate should absorb these effects.
} 


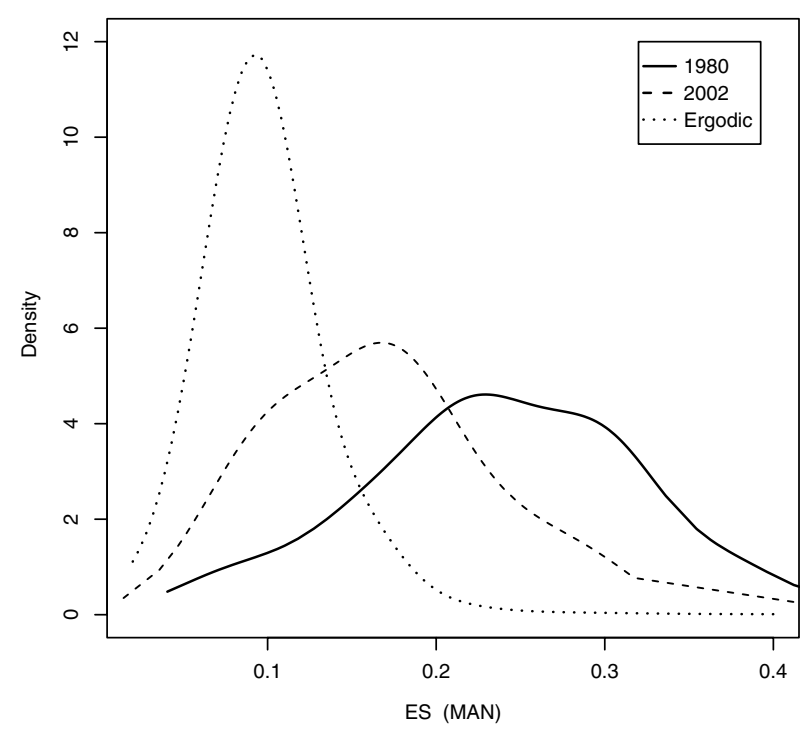

Fig. 9. Distribution dynamics of ES (MAN).

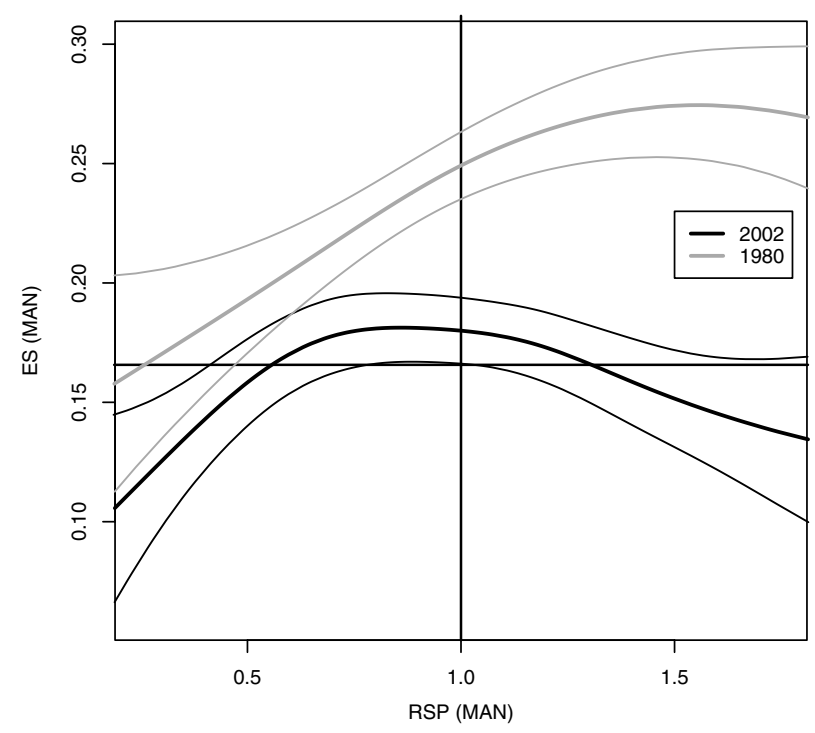

Fig. 10. Relationship between RSP and ES (MAN).

sion increases as well (see Fig. 13). Fig. 14 shows that decreasing returns characterize the relation between ES and RSP below average productivity; above average no clear patterns emerge. Fig. 15 shows that technological spillovers favor convergence at low and high levels of $\check{y}_{\mathrm{OS}}$. Hence, this sector contributes to nonconvergence in productivity by both sectoral productivity and sectoral employment shares. 


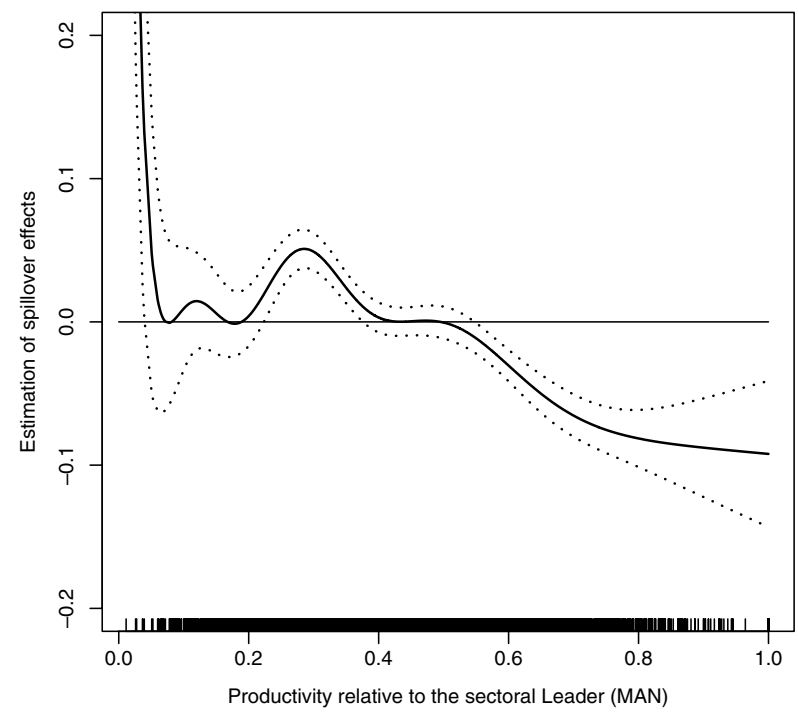

Fig. 11. Technological spillovers (MAN).

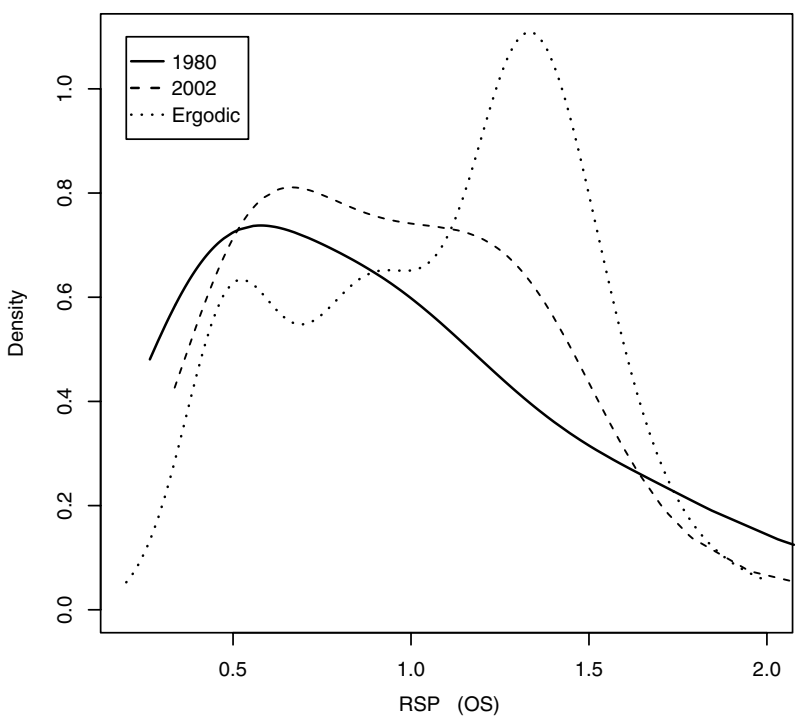

Fig. 12. Distribution dynamics of RSP (OS).

\subsubsection{Non Market Services}

Fig. 16 shows that there is no full convergence in RSP: dispersion is decreasing, but the peak of the distribution is remarkably below the average, and above average we find a relevant mass. ES is clearly increasing over time toward a single-peaked distribution (see Fig. 17). Fig. 18 highlights the existence of a threshold: in 2002, specialization effects prevail below the average, while decreasing returns dominate above the average (although the 


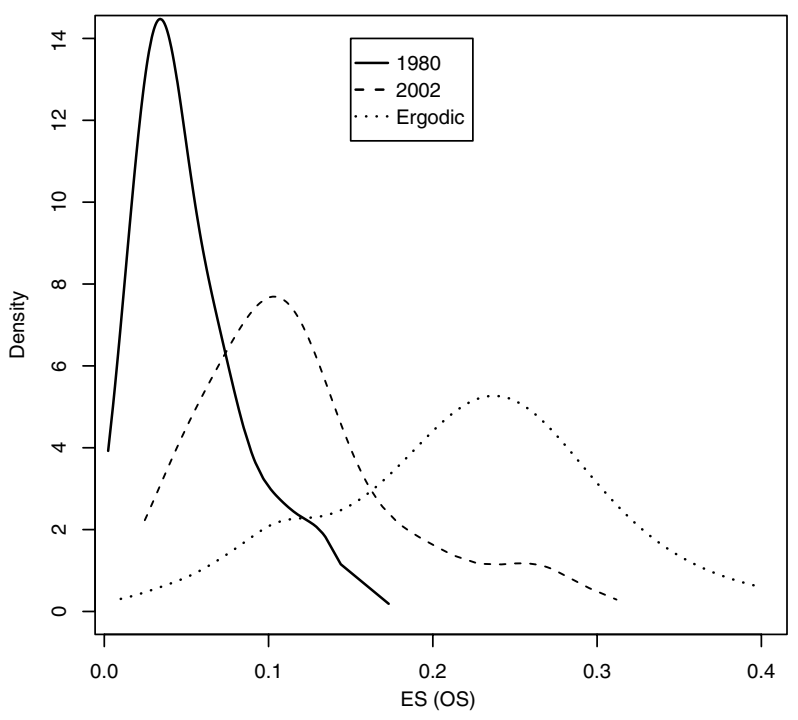

Fig. 13. Distribution dynamics of ES (OS).

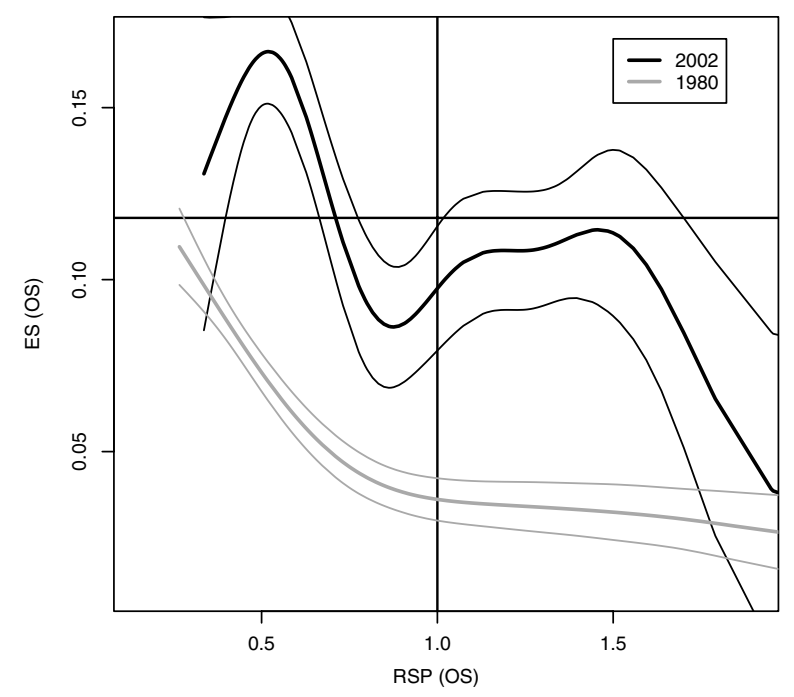

Fig. 14. Relationship between RSP and ES (OS)

confidence intervals are very large). The pattern of technological spillovers appears complex. Fig. 19 highlights that below approximately 0.4 regions do not benefit from spillovers. Above 0.4 a range of no spillovers appears, as $\hat{\lambda}_{\text {NMS }}$ is not statistically different from zero, while technological spillovers characterize only the highest levels of $\check{y}_{\mathrm{NMS}}$. Overall, this is compatible with the dynamics observed in Fig. 16, where regions seem to concentrate in two productivity ranges below and above the average. This result may depend on the strength of specialization effects in regions with low RSP. 


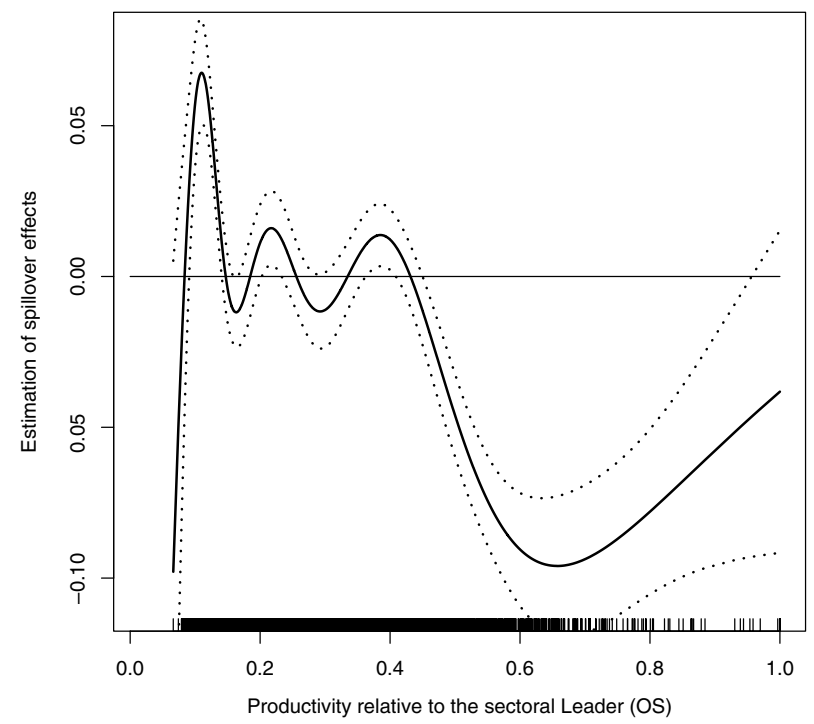

Fig. 15. Technological spillovers (OS).

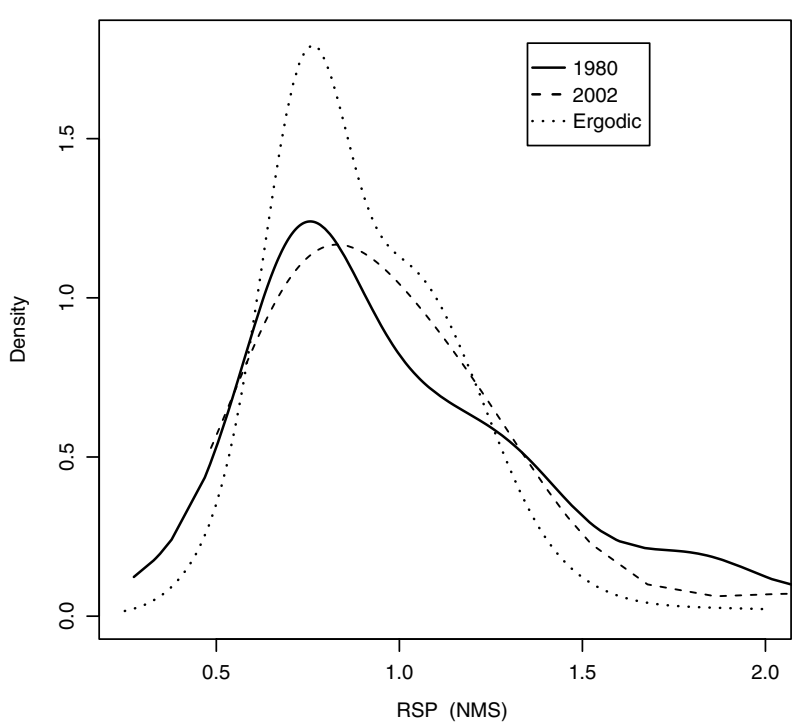

Fig. 16. Distribution dynamics of RSP (NMS).

Hence, in contrast with Corrado et al. (2005), we find that the services sector play an important role in the divergence in productivity across European regions.

\subsection{Sectoral contribution to growth}

The distribution of aggregate productivity may change even if the within-sector distribution is given, because the weights of individual sectors on aggregate output may change 


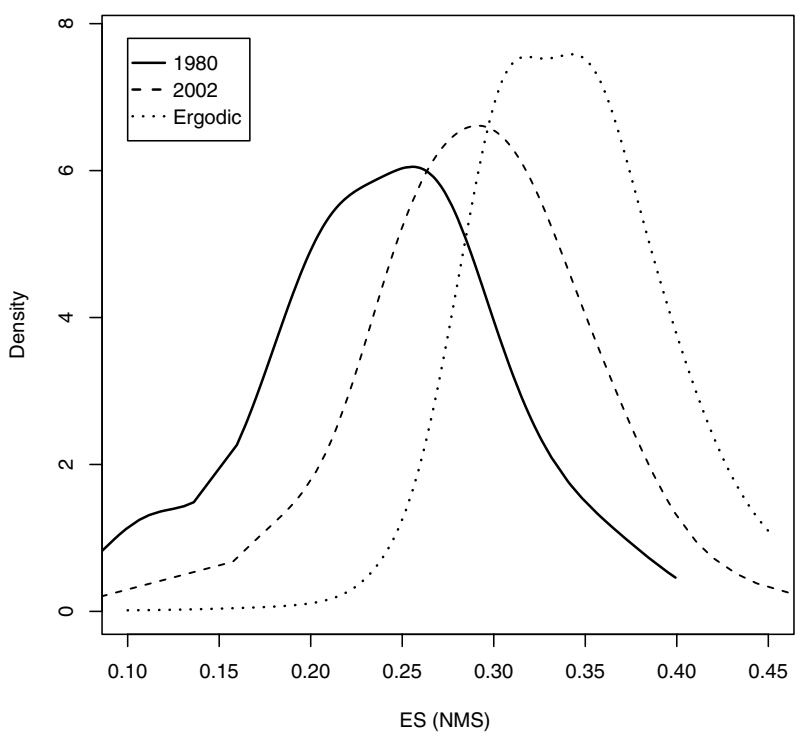

Fig. 17. Distribution dynamics of ES (NMS).

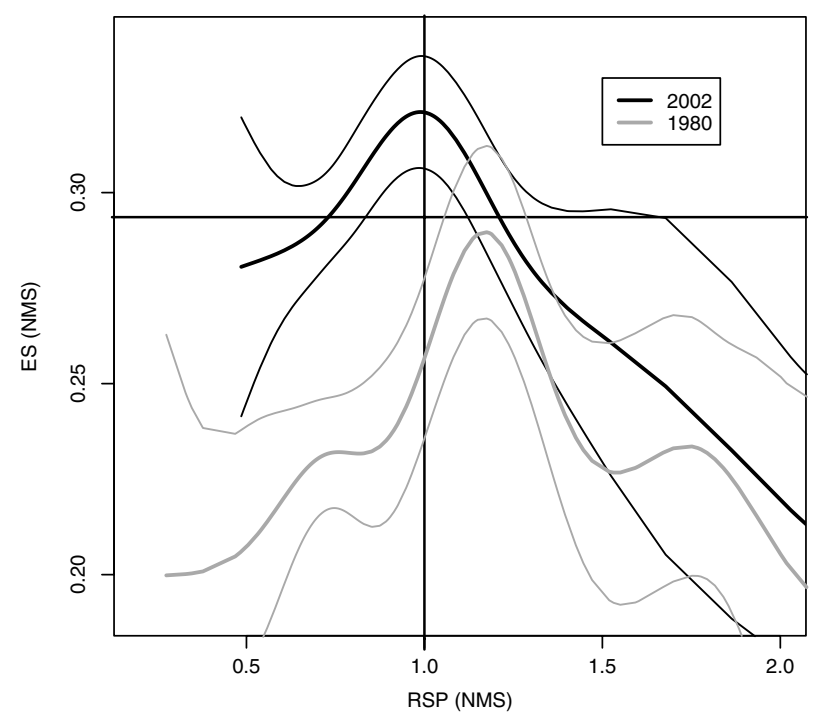

Fig. 18. Relationship between RSP and ES (NMS).

(e.g. the distribution of aggregate productivity, ceteris paribus, becomes more twin peaked if the weight of a sector with twin-peaked distribution of productivity increases). In this section we identify sectoral contributions to the aggregate rate of growth. This will provide with the final piece of information to evaluate the role of the sectors in the twin-peaked dynamics of aggregate productivity. 


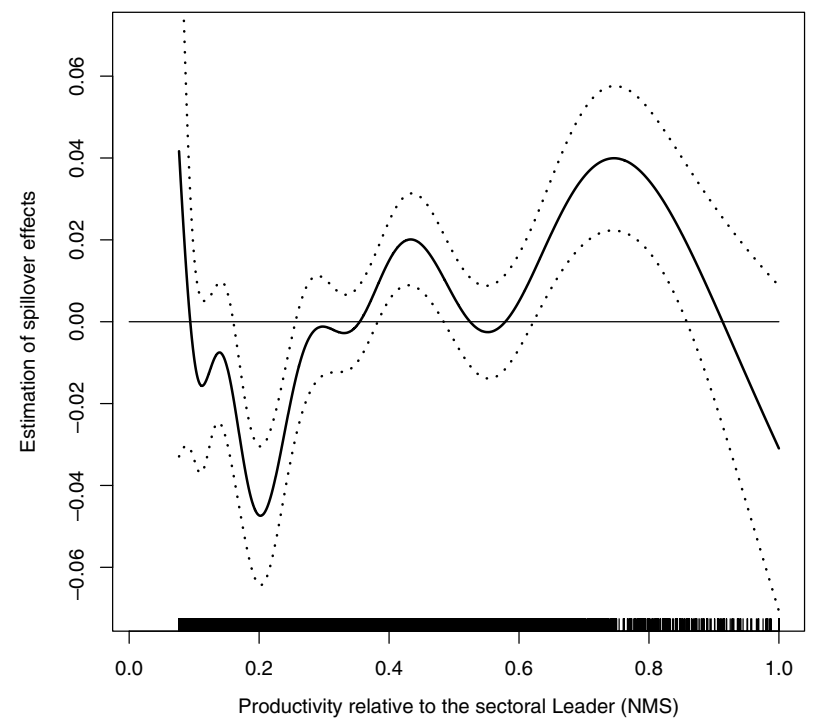

Fig. 19. Technological catching-up (NMS).

Aggregate productivity of an economy with $N$ sectors can be expressed as a weighted sum of sectoral productivities:

$$
y^{i}=\frac{Y^{i}}{L^{i}}=\sum_{j=1}^{N} \frac{Y_{j}^{i}}{L_{j}^{i}} \frac{L_{j}^{i}}{L^{i}}=\sum_{j=1}^{N} y_{j}^{i} \omega_{j}^{i} .
$$

Growth of aggregate productivity can be decomposed in changes in productivity of individual sectors and changes in employment shares. Following Bernard and Jones (1996a) we decompose the average growth rate of in two components, the productivity growth effect (PGE) and the share effect $(\mathrm{SE})$ :

$$
\underbrace{\frac{\Delta y^{i}(T) / y^{i}(0)}{T}}_{\text {PGE }} \equiv \underbrace{\frac{\sum_{j=1}^{N} \Delta y_{j}^{i}(T) \bar{\omega}_{j}^{i}(T)}{y^{i}(0)} / T}_{\mathrm{SE}}+\underbrace{\frac{\sum_{j=1}^{N} \bar{y}_{j}^{i}(T) \Delta \omega_{j}^{i}(T)}{y^{i}(0)} / T}_{\text {growth rate of } y^{i}},
$$

where $\Delta y^{i}(T)$ is the variation of productivity between 0 and $T, T=22$ (i.e. $T=2002-$ 1980) represents the number of years in the sample, $\bar{\omega}_{j}^{i}(T)=\left[\omega_{j}^{i}(T)+\omega_{j}^{i}(0)\right] / 2$ and $\bar{y}_{j}^{i}(t)=\left[y_{j}^{i}(T)+y_{j}^{i}(0)\right] / 2$ are respectively the average share and the average productivity over the period. ${ }^{29}$ PGE represents the growth of aggregate productivity due to the gains in productivity of individual sectors; SE represents the effect of changes in employment shares, i.e. of structural change (see Paci and Pigliaru, 1997), and TE the total effect of

\footnotetext{
${ }^{29}$ Calculating the average growth rate by dividing by $T$ represents a slight abuse. This explains the difference between the average growth rate of productivity reported in Table 7 and the value 1.68\% represented in Fig. 3 .
} 
Table 7

Decomposition of productivity growth (Bernard and Jones, 1996a)

\begin{tabular}{lcccccr}
\hline Sector & PGE & \%PGE & SE & \%SE & TE & \%TE \\
\hline AGR & 0.21 & 10.98 & -0.2 & -154.21 & 0.02 & 0.92 \\
MAN & 0.85 & 43.36 & -0.47 & -371.27 & 0.38 & 18.12 \\
MINEG & 0.48 & 24.38 & -0.43 & -339.71 & 0.05 & 2.21 \\
CONSTR & 0.06 & 3.08 & -0.04 & -33.66 & 0.02 & 0.85 \\
NMS & 0.15 & 7.43 & 0.25 & 200.25 & 0.4 & 19.17 \\
FIN & 0.04 & 2.21 & 0.04 & 33.47 & 0.09 & 4.11 \\
HOT & 0 & 0.17 & 0.07 & 58.73 & 0.08 & 3.74 \\
TRANSP & 0.19 & 9.71 & -0.01 & -7.33 & 0.18 & 8.67 \\
WHR & 0.18 & 9.38 & 0.06 & 46.89 & 0.24 & 11.66 \\
OS & -0.21 & -10.7 & 0.85 & 666.85 & 0.64 & 30.56 \\
Total & 1.95 & 100 & 0.13 & 100 & 2.08 & 100 \\
\hline
\end{tabular}

Sample averages for each sector.

each sector. Table 7 reports the average values across our 191 regions of the terms in Eq. (7).

The contribution of PGE to overall growth is remarkably predominant with respect to SE (1.95 vs 0.13 ). The growth rate is therefore almost completely attributable to technological advances within sectors. PGE mainly benefits from the increase in productivity in MAN, MINEG, AGR, TRANSP and WHR (in decreasing order), while the OS sector decreases its productivity over the period. SE benefits from the contribution of the OS and NMS sectors, but this is almost balanced by the negative contributions of the AGR, MAN and MINEG sectors. Overall, OS, MAN, NMS, WHR and TRANSP are, in decreasing order, the sectors contributing the most to the growth rate of productivity (taking together they explain almost $90 \%$ of the total).

\section{Summary of results and concluding remarks}

We have shown that the distribution of productivity in European regions tends to a bimodal distribution. Given this evidence, we defined two cluster of regions in correspondence to the two peaks. These clusters are characterized by different level of investment rate, density of economic activity, population density, and by a spatial component, which appears as essentially determined by country factors. In addition, we highlighted how the two clusters can be characterized by the composition of output and of employment shares.

Cross-section analysis showed that the initial composition of output can help to explain the nonlinearities in the growth path, where a higher share of output in 1980 in Manufacturing, Other Market Services, Transport and Communications, and Wholesale and Retail Services has a positive effect on growth rate, while a higher share in Hotels and Restaurants has a negative effect. In particular, Manufacturing and Other Market Services have a nonlinear impact.

The analysis of the dynamics of individual sectors and of their contribution to growth has revealed various forms of heterogeneity in their effect on aggregate productivity dynamics. Sectors that contribute the most to the twin peaks through nonconvergence in sectoral productivity dynamics are Manufacturing, Non Market Services, and Other Market Services, with different impacts according to their weights. Two other relevant 
findings are: (i) technological diffusion within sectors in neither automatic nor instantaneous, as already stressed for instance by Fagerberg and Verspagen (1996, p. 433); and (ii) spatial effects, much quoted in the recent literature, do not play specific roles once correct specifications are introduced.

\section{Acknowledgement}

We thank the editor of this special issue, Chris Papageorgiou, an anonymous referee for helpful suggestions, and Angela Parenti for excellent research assistance. Usual disclaimers aplly.

\section{Appendix A. Absolute $\beta$-convergence}

The presence of nonlinearities can be further demonstrated by comparing the results of regressions run in order to detect the presence of absolute $\beta$-convergence, that is a negative relation between the average annual growth rate and the initial level of productivity.

Eq. (8) specifies a linear relation between the average annual growth rate of a region and the initial level of productivity, while Eq. (9) allows such relation to be nonlinear:

$$
\begin{aligned}
& {\overline{\mathrm{PROD} . \mathrm{GR}^{i}}}^{i}=\alpha+\beta \log \left(\mathrm{PROD} \cdot \mathrm{REL} 1980^{i}\right)+\epsilon^{i}, \\
& {\overline{\mathrm{PROD} \cdot \mathrm{GR}^{i}}}^{i}=\alpha+s\left(\log \left(\mathrm{PROD} \cdot \mathrm{REL} 1980^{i}\right)\right)+\epsilon^{i} .
\end{aligned}
$$

Regions' productivities display absolute $\beta$-convergence if $\hat{\beta}$ is negative or, in a more general way, $\hat{\mathrm{s}}(\cdot)$ crosses from above and only once the line of the average growth rate of the sample in a range around 1.

Results in Table 8 reveal the presence of absolute $\beta$-convergence, given that $\hat{\beta}$ is negative and statistically different from zero. Given $\hat{\beta}$, the rate of convergence is equal to $0.012 .^{30}$

The estimate of Eq. (9), however, shows that the relationship between the average growth rate and initial level of productivity is significantly nonlinear (EDF are equal to 8.1). Fig. 20 reports the estimated relationships for the parametric and nonparametric specifications of Eqs. (8) and (9). The estimated relationship from the linear specification lies almost entirely in the confidence interval of the nonparametric estimation, but in the proximity of the inflection point slightly below one. Although $\hat{\beta}$ is highly significant, the parametric specification fails to capture crucial nonlinearities. The parametric estimate suggests the existence of a tendency to converge to a globally stable equilibrium, a fact that is not corroborated by the nonparametric estimation of Eq. (9). This drawback typically affects cross-section regressions as emphasized by Bernard and Durlauf (1996, p. 167): when data generation process admits multiple equilibria, the estimate of Eq. (8) may wrongly detect $\beta$-convergence (both absolute and conditional).

\footnotetext{
${ }^{30}$ The estimated rate of convergence is equal to $-\log [1+(\hat{\beta} T)] / T$, where $T$ is the number of periods (see Barro and Sala-i-Martin, 2004).
} 
Table 8

Estimation of Eqs. (8) and (9)

\begin{tabular}{llll}
\hline & Eq. (8) & & Eq. (9) \\
\hline Param. coeff. & & Param. coeff. & \\
$\hat{\alpha}$ & $0.016^{* * *}$ & $\hat{\alpha}$ & $0.017^{* * *}$ \\
$\hat{\beta}$ & $-0.011^{* * *}$ & - & - \\
& & Nonparam. coeff. & $8.1^{* * *}$ \\
& & $\log ($ PROD.REL1980) & Dev. exp. $=0.42$ \\
Obs. $=191$ & & GCV $\left(\times 10^{3}\right)=0.028$ & $\bar{R}^{2}=0.39$ \\
\hline
\end{tabular}

${ }^{* * *}$ Indicates significance at $1 \%$ level. Dependent variable $\overline{\text { PROD.GR. For nonparametric coefficient we report }}$ EDF (see Appendix B).

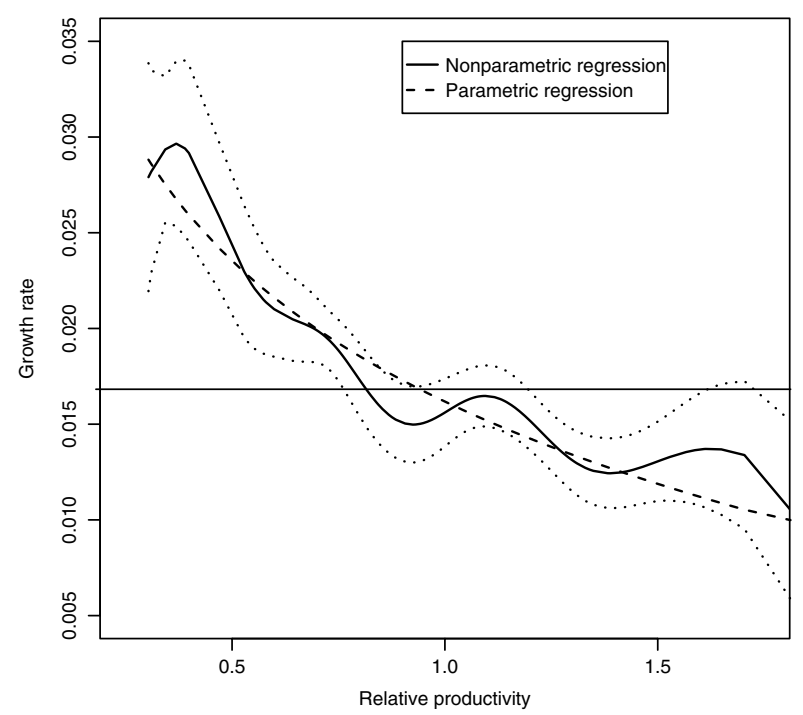

Fig. 20. Absolute convergence across the regions' productivity. The horizontal line indicates the sample average.

\section{Appendix B. GAM estimation}

We estimate Eq. (2) following the method described in Wood (2006), and implemented by the package $m g c v$ in R. The estimation is obtained by penalized likelihood maximization. The model is fitted by minimizing:

$$
\|\mathbf{y}-\mathbf{X} \boldsymbol{\beta}\|^{2}+\sum_{k=1}^{K} \lambda_{k} \int_{0}^{1}\left[s_{k}^{\prime \prime}(x)\right]^{2} \mathrm{~d} x,
$$

where $\mathbf{y}$ is the vector of observations ( $\overline{\mathrm{PROD} . G R}^{i}$ in our case), $\mathbf{X}$ is the matrix of explanatory variables, $\boldsymbol{\beta}$ is a vector of parameters to be estimated, $\lambda_{k}, k=(1, \ldots, K)$, are smoothing parameters, and the penalty, which controls the smoothness of the estimate, is 
represented by the integrated square of second derivatives of the smooth terms. The vector of parameters $\boldsymbol{\beta}$ originates from expressing every smooth term in Eq. (2), s(·), as

$$
s_{k}(x)=\sum_{i=1}^{q} b_{i}(x) \boldsymbol{\beta}_{i},
$$

where $b_{i}(x)$ are basis functions and $q$ is their number.

Parameters $\boldsymbol{\beta}_{i}$ are chosen to minimize the function in Eq. (10) for given values of the smoothing parameters $\lambda_{k}$ (it is possible to show that the penalty can also be expressed as a function of $\boldsymbol{\beta}$ ). Smoothing parameters are in turn chosen by minimization of the Generalized Cross Validation (GCV) score. Estimation proceeds by Penalized iteratively reweighted least squares, until convergence in the estimates is reached.

In the results of the estimations, we report: (1) the estimated degrees of freedom for each term (EDF). The EDF reflect the flexibility of the model. When the EDF of a term are equal to one, the term can be substituted by a linear function. (2) The adjusted $R^{2}$, having the familiar interpretation. (3) The proportion of Deviance explained, a generalization of $R^{2}$. (4) The Scale parameter estimation, corresponding to the residual variance of the estimation. (5) The GCV score, which provides the fundamental information on the specification of the model. The decision to remove or maintain a term is based on comparison of GCV scores, and the model which minimizes the GCV with the lowest number of terms is preferred.

\section{References}

Anselin, L., 1995. Local indicators of spatial association - LISA. Geographical Analysis 27, 93-115.

Barro, R.J., Sala-i-Martin, X., 1991. Convergence across states and regions. Brooking Papers on Economic Activity, 107-182.

Barro, R.J., Sala-i-Martin, X., 2004. Economic Growth, second ed. MIT Press.

Bernard, A., Durlauf, S.N., 1996. Interpreting Tests of Convergence Hypothesis. Journal of Econometrics 71, $161-173$.

Bernard, A.B., Jones, C.I., 1996a. Productivity and convergence across US states and industries. Empirical Economics 21, 113-135.

Bernard, A.B., Jones, C.I., 1996b. Comparing apples to oranges: Productivity convergence and measurement across industries and countries. American Economic Review 86, 1216-1238.

Bowman, A.W., Azzalini, A., 1997. Applied Smoothing Techniques for Data Analysis. Clarendon Press, Oxford. Cambridge Econometrics, 2004. European Regional Prospects. Analysis and Forecast. CD ROM, Cambridge.

Ciccone, A., Hall, R.E., 1996. Productivity and the density of economic activity. American Economic Review 86, 54-70.

Corrado, L., Martin, R., Weeks, M., 2005. Identifying and interpreting regional convergence clusters across Europe. The Economic Journal 115, 133-160.

Efron, B., Tibshirani, R., 1993. An Introduction to the Bootstrap. Chapman and Hall, London.

Esteban, J., 2000. Regional convergence in Europe and the industrial mix: A shift-share analysis. Regional Science and Urban Economics 30, 353-364.

European Commission, 2004. A New Partnership for Cohesion: Convergence, Competitiveness, Cooperation: Third Report on Social Cohesion. European Commission, Luxembourg.

Fagerberg, J., Verspagen, B., 1996. Heading for divergence? Regional growth in Europe reconsidered. Journal of Common Market Studies 34, 431-448.

Feyrer, J., 2003. Convergence by Parts, mimeo, Dartmouth College.

Fiaschi, D., Lavezzi, A.M., 2007. Productivity polarization and sectoral dynamics in European regions. Discussion Papers, no. 63, University of Pisa.

Galor, O., 1996. Convergence? Inferences from theoretical models. Economic Journal 106, 1056-1069. 
Johnson, P.A., 2005. A continuous state space approach to 'convergence by parts'. Economic Letters 86, 317-321.

Le Gallo, J., Dall'Erba, S., 2005. Spatial and sectoral productivity convergence between European regions, 19722000, mimeo.

López-Bazo, E., Vayá, E., Mora, A.J., Surinach, J., 1999. Regional economic dynamics and convergence in European union. The Annals of Regional Science 33, 343-370.

Magrini, S., 2004. Regional (di)convergence. In: Henderson, J.V., Thisse, J.F. (Eds.), Handbook of Regional and Urban Economics. Elsevier.

Mankiw, N.G., Romer, D., Weil, D., 1992. A contribution to the empirics of economic growth. Quarterly Journal of Economics 107, 407-437.

Ord, J.K., Getis, A., 1995. Local spatial autocorrelation statistics, distributional issue and an application. Geographical Analysis 27, 286-305.

Paci, R., Pigliaru, F., 1997. European regional growth: Do sectors matters? In: Adams, J., Pigliaru, F. (Eds.), Economic Growth and Change. National and Regional Patterns of Convergence and Divergence. Edward Elgar, Cheltenham.

Quah, D.T., 1997. Empirics for growth and distribution: Stratification, polarization, and convergence clubs. Journal of Economic Growth 2, 27-59.

R Development Core Team, 2004. R: A language and environment for statistical computing. R Foundation for Statistical Computing, Vienna, Austria. ISBN: 3-900051-07-0, URL: http://www.R-project.org.

Silverman, B.W., 1986. Density Estimation for Statistics and Data Analysis. Chapman \& Hall, London.

Wood, S.N., 2006. Generalized Additive Models. An Introduction with R. Chapman and Hall, London.

World Bank, 2004. World Development Indicators. 